\title{
SHAPE OPTIMIZATION OF CATALYST PELLETS FOR THE IMPROVEMENT OF SYNTHESIZING PROCESS OF ENVIRONMENTALLY FRIENDLY REFRIGERANTS
}

\author{
JIHONG LIU' ${ }^{1}$ AND DAISUKE KARUBE ${ }^{2}$ \\ ${ }^{1}$ Technology and Innovation Center \\ Daikin Industries, Ltd. \\ 1-1 Nishi-Hitotsuya, Settsu, Osaka 566-8585, Japan \\ jihong.liu@daikin.co.jp,www.daikin.com \\ ${ }^{2}$ Chemicals Division \\ Daikin Industries, Ltd. \\ 1-1 Nishi-Hitotsuya, Settsu, Osaka, 566-8585 Japan \\ daisuke.karube@daikin.co.jp,www.daikin.com
}

Key words: Catalyst Pellet Shape, Pipe Reactor, Bulk Density, Stress, Simulation, FEM.

\begin{abstract}
In this paper, we utilized a simulation approach based on the dynamic explicit FEM (Finite Element Method) to evaluate the stress distributions and the bulk density of catalyst pellets filled in a pipe reactor. We clarified that the shape of catalyst pellets affects their bulk density and stress distribution and found an optimal catalyst pellet shape that can increase the bulk density and reduce the average stress in the pipe reactor. The optimally shaped catalyst pellets are expected to improve their filled state in the pipe reactor, extend the durability of the catalyst pellets and increase the efficiency of production of environmentally friendly refrigerants. At the same time, the proposed simulation method can contribute to speeding up the development of production equipment and improving its completeness.
\end{abstract}

\section{INTRODUCTION}

Daikin is the only manufacturer of air conditioners in the world that also produces refrigerants at the same time. We are not only developing refrigerants with low environmental impact, but also improving the refrigerant synthesis process with low environmental impact.

The production technology of refrigerants by vapor phase reaction (VPR) is frequently used to produce refrigerant compounds. The efficiency of VPR depends on not only the catalyst activity but also the uniformity and the bulk density of an aggregate of catalyst pellets filled in a reactor. In general, catalyst pellets are particles in a few millimeters made from the catalytic substance and are used to hold catalyst in a reactor for VPR. As shown in Fig.1, there are usually two types of catalyst pellet shapes. One is a spherical shape, and another is a cylindrical shape [1,2]. In this paper, we deal with the cylindrical catalyst pellets that are often used in VPR.

Figure 2 shows the schematic diagram of catalyst pellets used for VPR in a pipe reactor. If the uniformity of the filled state of catalyst pellets is low, the staring materials will selectively 
flow through low-density part of an aggregate of catalyst pellets without enough contact with the catalyst pellets. This will result in low VPR conversion efficiency. If the bulk density of the aggregate of filled catalyst pellets is too high, the internal pressure in the pipe reactor may become too high due to high resistance to the gas flow. This may cause the degradation of reaction conversion efficiency and/or selectivity. So, the uniformity and the bulk density of the catalyst pellets in a pipe reactor are important for efficient VPR.

In order to maximize the VPR conversion efficiency, it is important to determine the shape and size of the catalyst pellets suitable for the dimension of a pipe reactor. This is because that the shape and size affect the uniformity and bulk density of the catalyst pellets in the pipe reactor. In addition, the shape and size also affect the stress distribution of the catalyst pellets in the pipe reactor. The catalyst pellets in the bottom of the pipe reactor may be crushed by the weight of the top ones. This may increase pressure loss of the pipe reactor and the catalyst pellets at the bottom of the pipe reactor may become difficult to be used during the VPR anymore. Until now, the shape and size of the catalyst pellets have been determined by empirical rules and experiments, which are time consuming and costly.
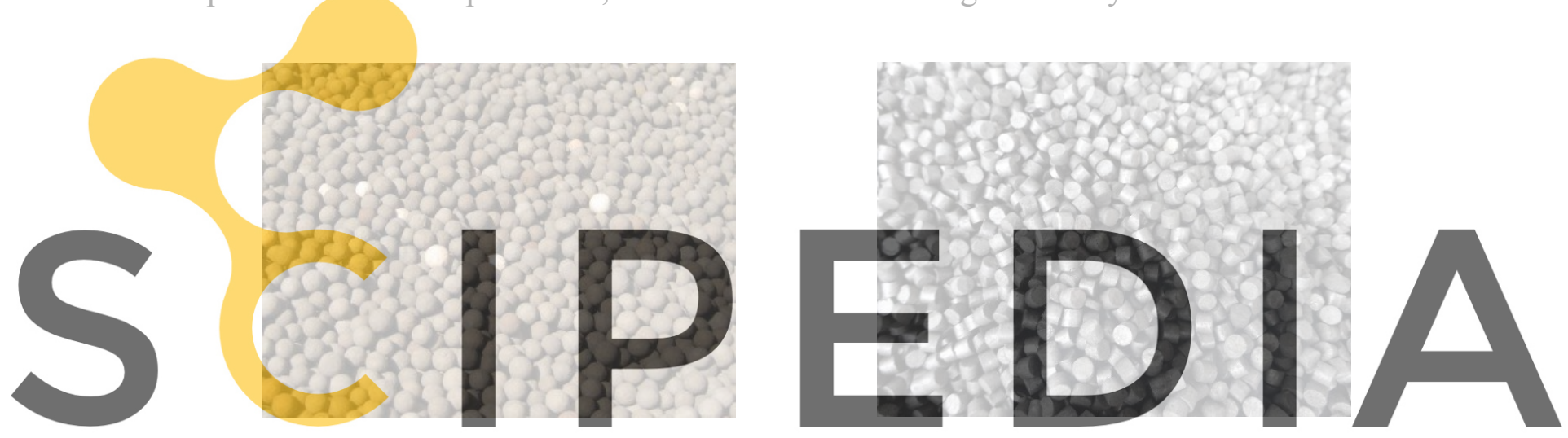

Figure 1: Catalyst pellets with sphrecial shape (left) and cylindrical shape (right)

Register for free at https//www.scipedia.com to download the version without the watermark

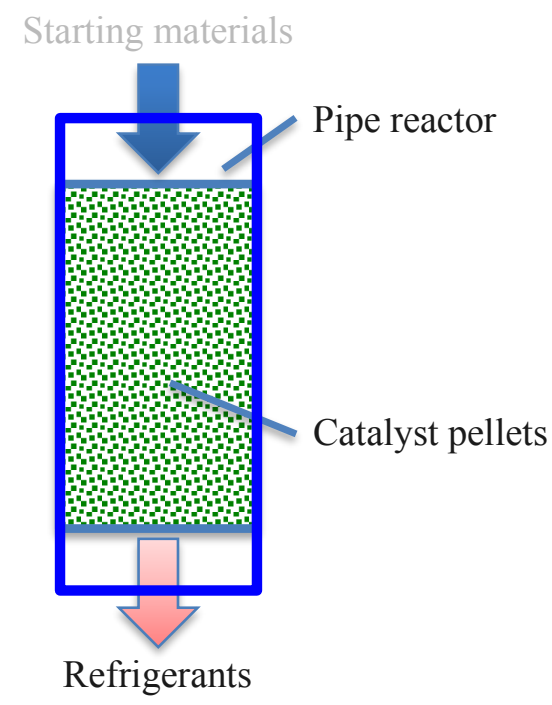

Figure 2: Schematic diagram of catalyst pellets filled into a pipe reactor for the VPR 
Therefore, if the appropriate range of the shape and size of the catalyst pellets, that can be uniformly filled into a pipe reactor with a predetermined bulk density, can be clarified by the simulation results, it will be possible to accelerate the development of refrigerant production equipment by shifting development method from experiment-centric to simulation-driven.

The purpose of this study is to propose a simulation method of filling catalyst pellets into a pipe reactor. In this paper, we applied the resin pellet flow simulation technology [3-5] based on the dynamic explicit FEM to the filling simulation of catalyst pellets into a pipe reactor. We clarified that the stress distribution and bulk density of the catalyst pellets in the pipe reactor, and found an optimal shape of the catalyst pellets that can improve the uniformity and the bulk density of the catalyst pellets in the pipe reactor, and maximize refrigerant synthesis efficiency to reduce the environmental burden.

\section{SIMULATION OF FILLING CATALYST PELLETS INTO A PIPE REACTOR}

In this paper, we propose the simulation method of filling an aggregate of catalyst pellets into a pipe reactor based the explicit FEM [3-5]. The simulation method has three steps. The first step is to create a randomly filled state of the catalyst pellets in a pipe reactor. The second step is to calculate the bulk density and stress distribution of the catalyst pellets in the pipe reactor. The third step is to evaluate the effect of shape of catalyst pellets on their filled state.

\subsection{Simulation model}

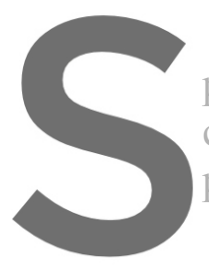

The cylindrical cata paper, we define a par cylindrical catalyst pel pellet is $3 \mathrm{~mm}$ in diamet The pipe reactor and
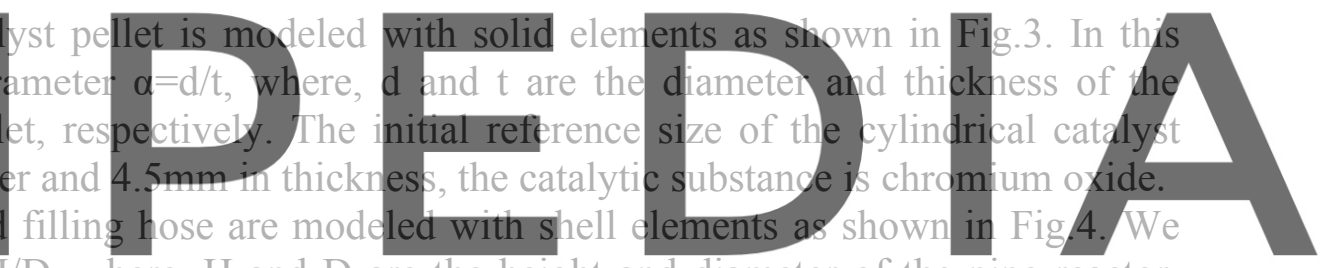

define a parameter $\gamma=\mathrm{H} / \mathrm{D}$, where, $\mathrm{H}$ and $\mathrm{D}$ are the height and diameter of the pipe reactor,

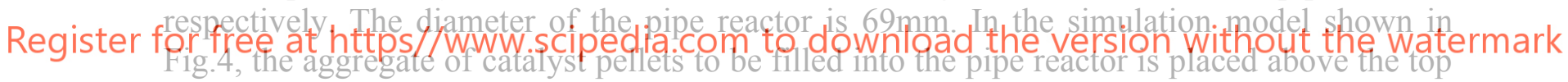
of the filling hose, which has a hopper-shaped inlet for easy inflow of the catalyst pellets.

In the simulation, we assumed that the aggregate of catalyst pellets free-falls in the filling hose, and at the same time we pull up the filling hose to flow the catalyst pellets into the pipe reactor. This will create a random filled state of the catalyst pellets in the pipe reactor [3].

\subsection{Effect of the ratio of height to thickness of a pipe reactor}

In this section, we show the simulation results of filling catalyst pellets into a pipe reactor with different $\gamma$, the ratio of height to diameter. LS-DYNA [6] is used for the simulations.
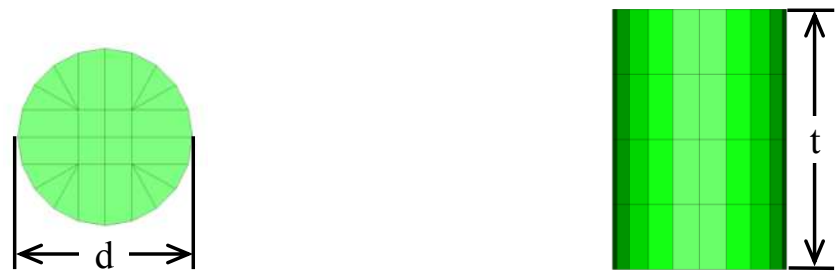

Figure 3: A cylindrical catalyst pellet modelled with solid elements 
Figure 5 shows the average equivalent stress distribution of catalyst pellets filled into pipe reactors with different $\gamma$. The horizontal axis is $\gamma$, and the vertical axis is the average stress. It is found that the maximum average stress occurs at the bottom of the pipe reactors and approaches almost constant value when $\gamma$ is greater than about 6 . This means that when the height of filled catalyst pellets exceeds about 6 times the diameter of pipe reactor, the average stress of the catalyst pellets at the bottom of the pipe reactor becomes almost constant value.

Figure 6 shows the equivalent stress distribution in the process of filling the catalyst pellets into the pipe reactor. It is seen that after the filling hose is filled with the free-falling catalyst pellets, the filling hose is pulled up and the catalyst pellets are filled into the pipe reactor, and the stress of catalyst pellets at the bottom of pipe reactor is greater than that at the top.
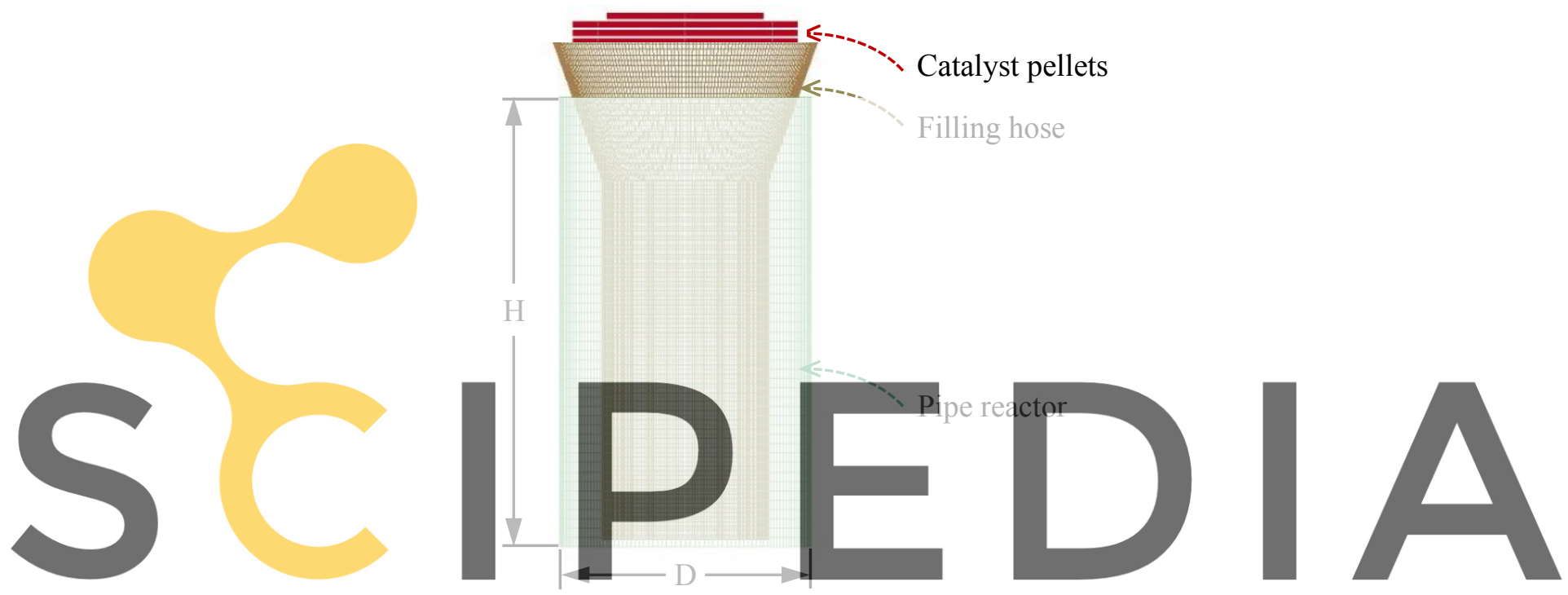

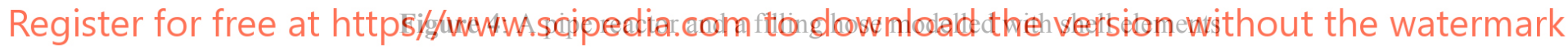

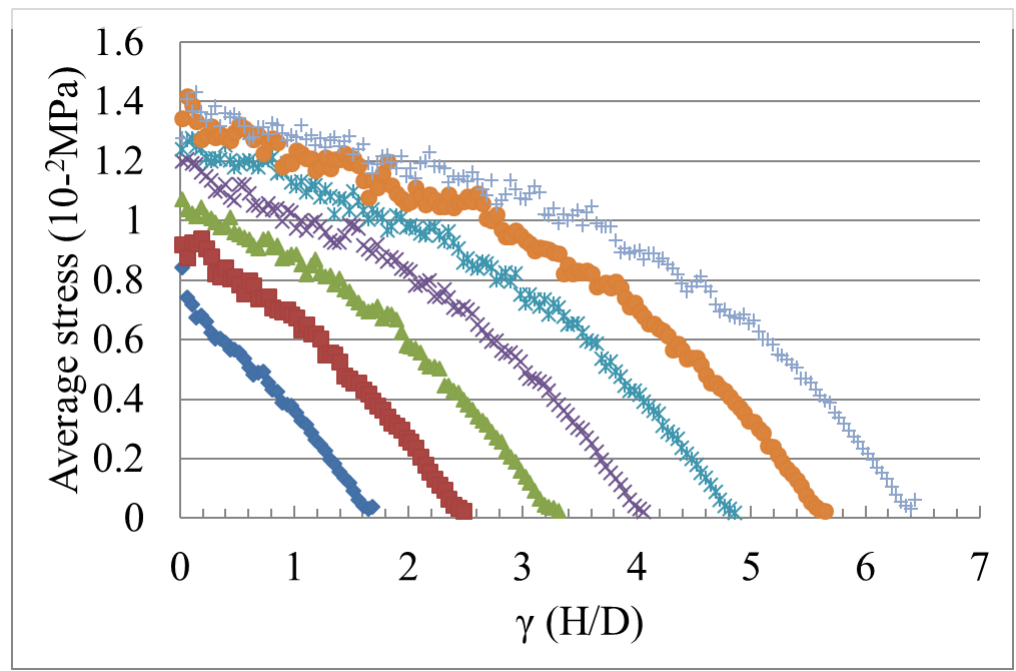

Figure 5: Average equivalent stress distribution of the catalyst pellets in pipe reactors with different $\gamma$ 

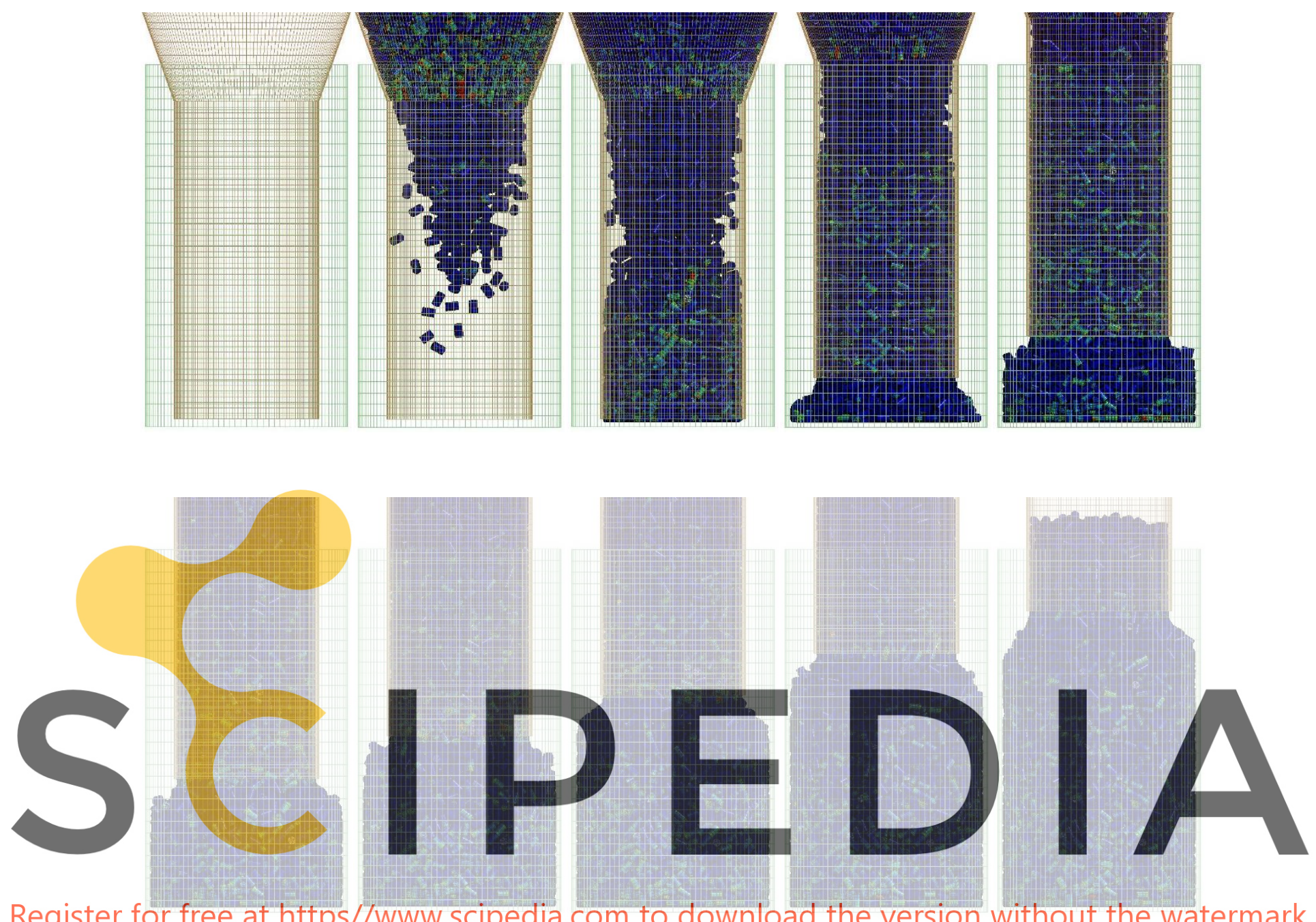

Register for free at https//wwW.scipedia.com to download the version without the watermark
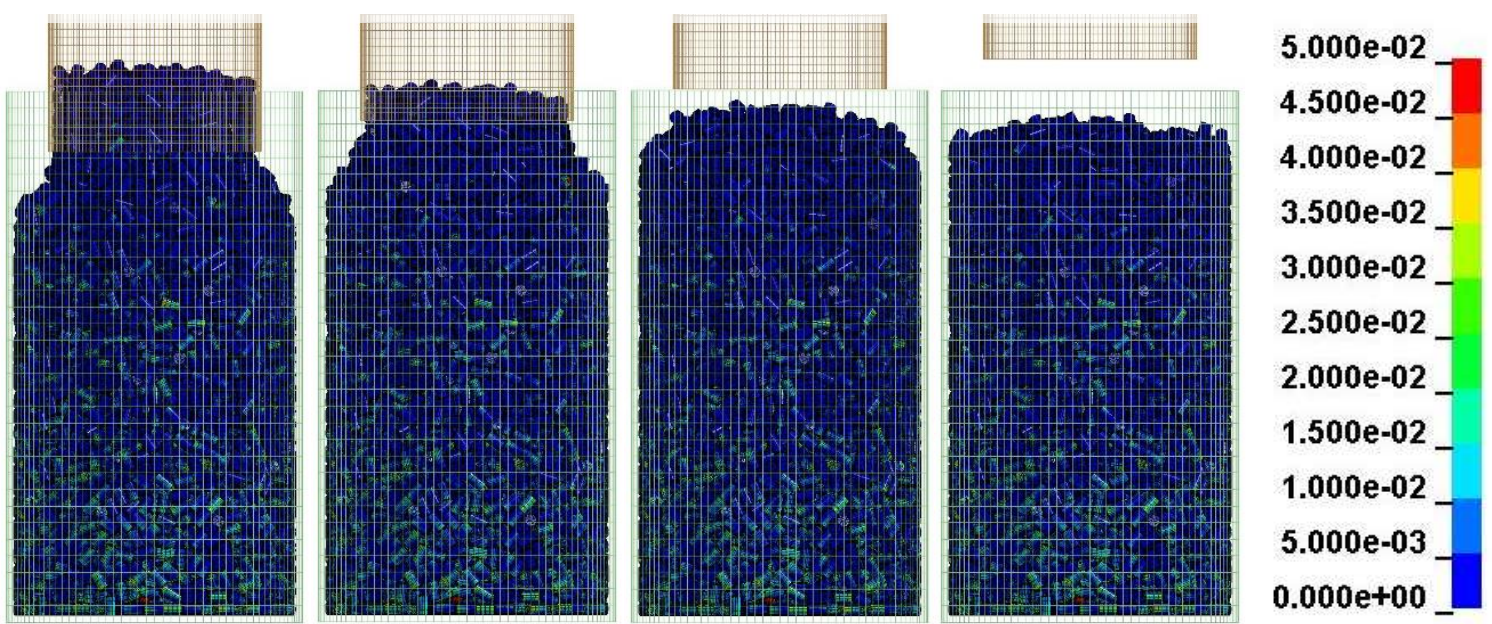

Figure 6: Equivalent stress distribution in the process of filling catalyst pellets into the pipe reactor 


\subsection{Effect of the ratio of diameter to thickness of a cylindrical catalyst pellet}

In this section, we show the simulation results of filling cylindrical catalyst pellets with different $\alpha$, the ratio of diameter to thickness, into the pipe reactor.

Figure 7 shows the shapes and finite element divisions of isovolumetric cylindrical catalyst pellets with different $\alpha$. When $\alpha$ is small, the shape becomes an elongated cylinder, and when $\alpha$ is large, the shape becomes a thinner disk. Note that the cylindrical catalyst pellets with different $\alpha$ have the same volume.

Figure 8 indicates the bulk density of the catalyst pellets with different $\alpha$ that are filled in the pipe reactor. The horizontal axis is $\alpha$, and the vertical axis is the bulk density. It is found that the bulk density reaches the highest value when $\alpha$ is about 1.1 . This means that the catalyst pellets can be finely filled into the pipe reactor when $\alpha$ is about 1.1. In addition, it is clear that when $\alpha$ is less than 1.1 , the bulk density of the catalyst pellets drops sharply, and it can also be seen that when $\alpha$ is greater than 1.1 , the bulk density of the catalyst pellets decreases relatively slowly.

Figure 9 displays the average equivalent stress of the catalyst pellets with different $\alpha$ that are filled in the pipe reactor. It is found that the average equivalent stress reaches the smallest value when $\alpha$ is about 1.1. This means that the gravity of the catalyst pellets is well dispersed on the walls of the pipe reactor when $\alpha$ is about 1.1, and this leads to a reduction in stress of the catalyst pellets at the bottom of the pipe reactor.

From the above-mentioned simulation results, it is clarified that the bulk density is the

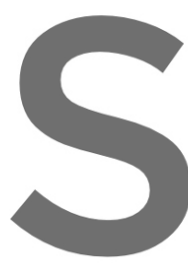
maximum value and about 1.1. That is, whe filled state of the cataly is also improved due
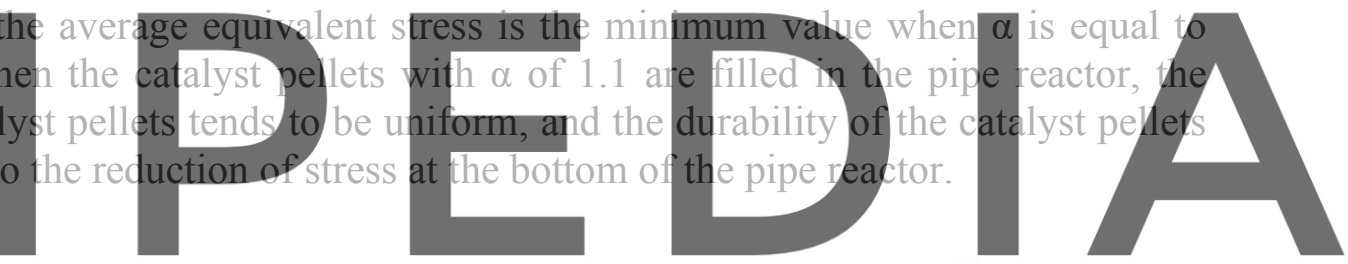

Register for free at https//www.scipedia.com to download the version without the watermark
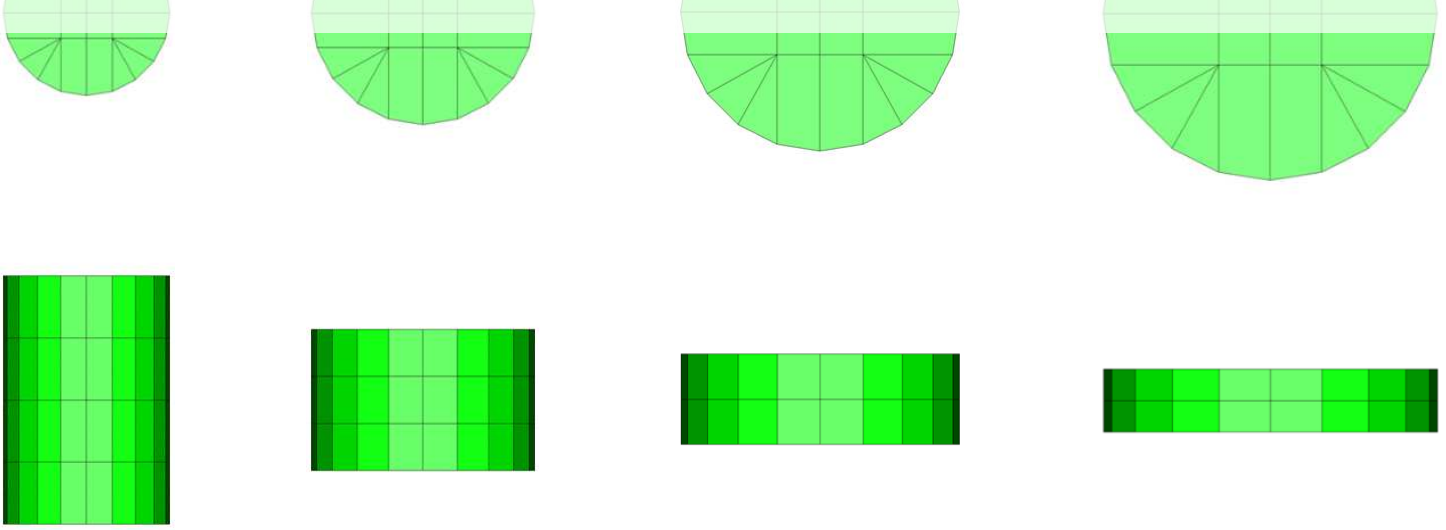

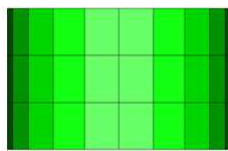

$\alpha 1.58$

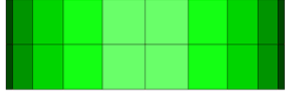

$\alpha 3.09$

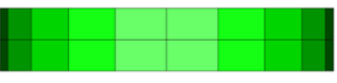

$\alpha 5.31$

Figure 7: Shapes and finite element divisions of the isovolumetric cylindrical catalyst pellets with different $\alpha$, the ratio of diameter to thickness 
Figure 10 shows the filled state of the catalyst pellets with different $\alpha$ in the pipe reactor. It is seen that the bulk density and the equivalent stress distribution of the catalyst pellets filled in the pipe reactor change depending on $\alpha$. For example, it can be seen from this figure that the bulk density of the catalyst pellets with $\alpha$ of 5.31 is lower than that with $\alpha$ of 1.58 . On the other hand, it is also clear from this figure that the stress of the catalyst pellets when $\alpha$ is 5.31 is significantly higher than that when $\alpha$ is 1.58 . Therefore, in order to ensure the durability of the catalyst pellets filled in the pipe reactor, it seems that the use of catalyst pellets with $\alpha$ of 3 or more should be avoided.

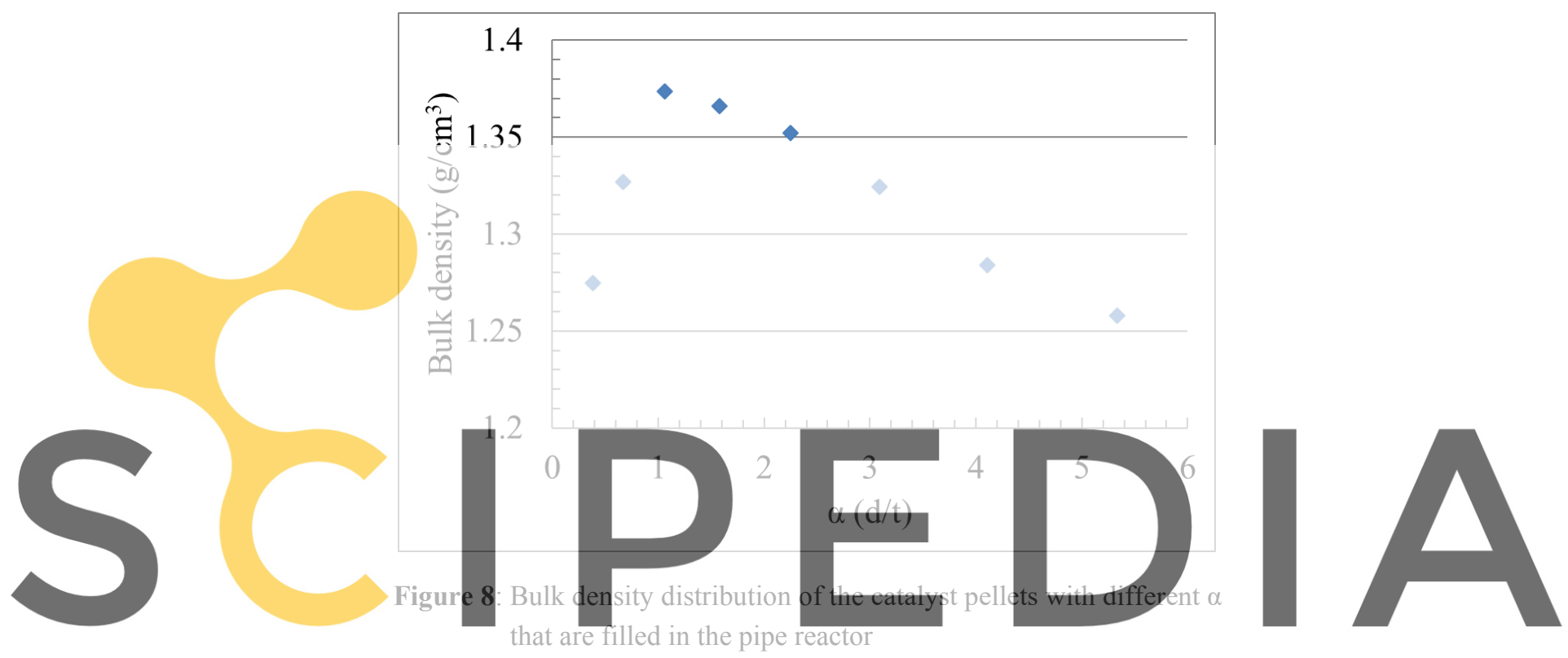

Register for free at https//www.scipedia.com to download the version without the watermark

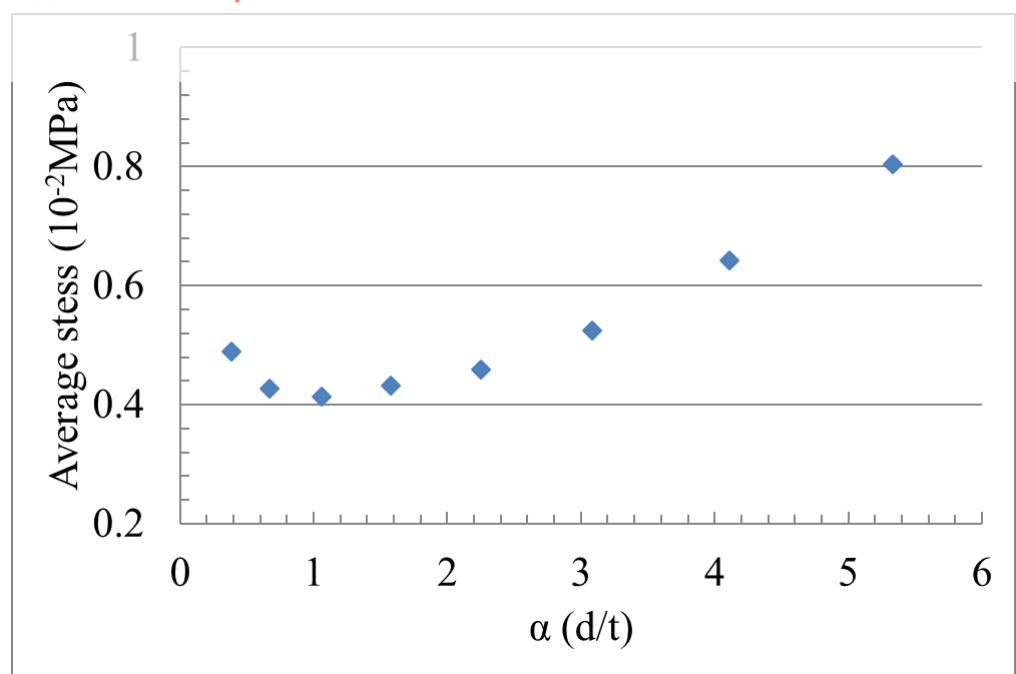

Figure 9: Average equivalent stress distribution of the catalyst pellets with different $\alpha$ that are filled in the pipe reactor 

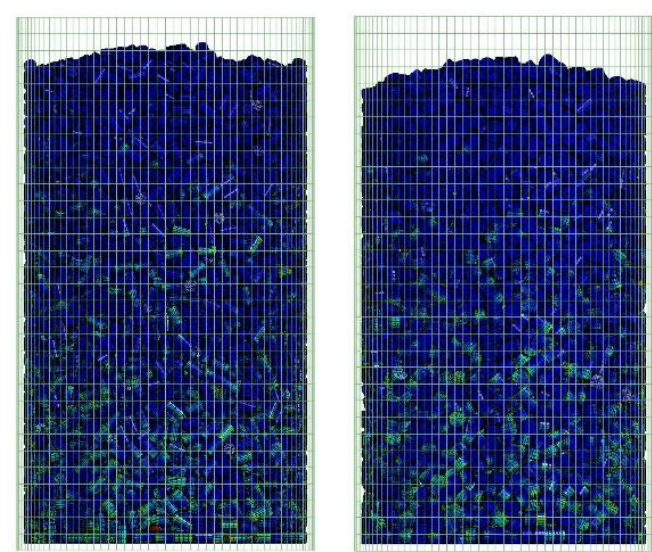

$\alpha 0.67$

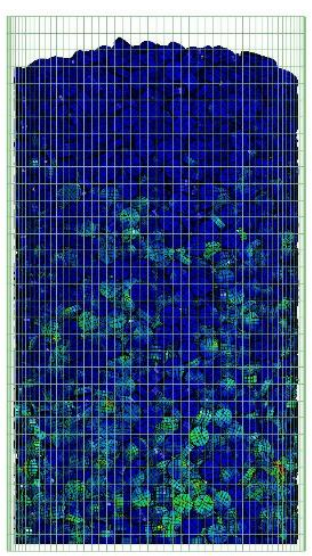

$\alpha 3.09$

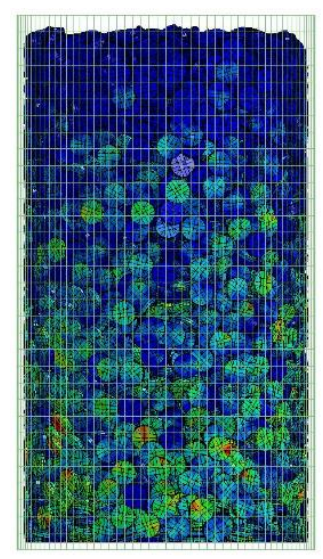

5.000e-02

4.500e-02

4.000e-02

$3.500 \mathrm{e}-02$ 3.000e-02

2.500e-02

2.000e-02

1.500e-02 $1.000 \mathrm{e}-02$

$5.000 \mathrm{e}-03$

$0.000 \mathrm{e}+00$

$\alpha 5.31$

Figure 10: Equivalent stress distribution of the catalyst pellets with different $\alpha$ filled in the pipe reactor

\subsection{Effect of the ratio of major-minor axis of an elliptic cylindrical catalyst pellet}

In this section, we show the simulation results of filling elliptic cylindrical catalyst pellets with different ratio of major axis to minor axis into the pipe reactor.

Figure 11 shows the cross-section shape and finite element divisions of an isovolumetric elliptic cylindrical catany minor axis of the cross-section of the elliptic cross-section is a circle. When $\beta$ is not equal to 1 in elliptic section with different $\beta$ have the sane volume. Here, section areas are equal, that is, $\left[(\mathrm{d} / 2)^{\wedge} 2\right] \pi$ is equal to $(\mathrm{ab} / 4) \pi$.

Figure 12 indicates the bulk density ratio of the elliptic

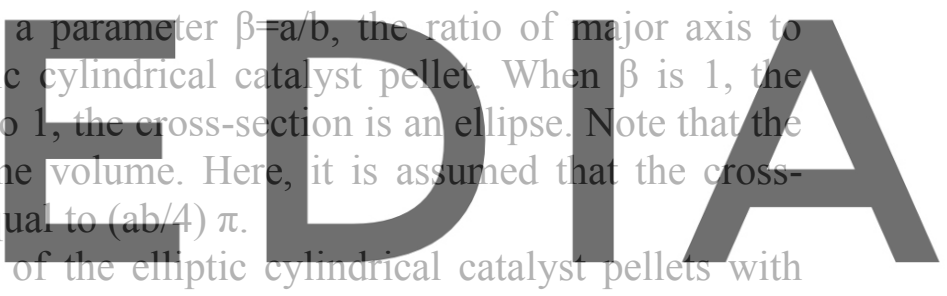
different $\beta$ to circular cylindrical catalyst pellets. The horizontal axis is $\beta$, and the vertical axis

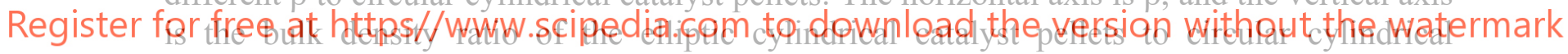
catalyst pellets. It is found that the bulk density reaches the highest value when $\beta$ is about 1.45.

Compared to the circular cylindrical catalyst pellets, the elliptic cylindrical catalyst pellets with $\beta$ of about 1.45 have a further $2 \%$ increase in the bulk density.
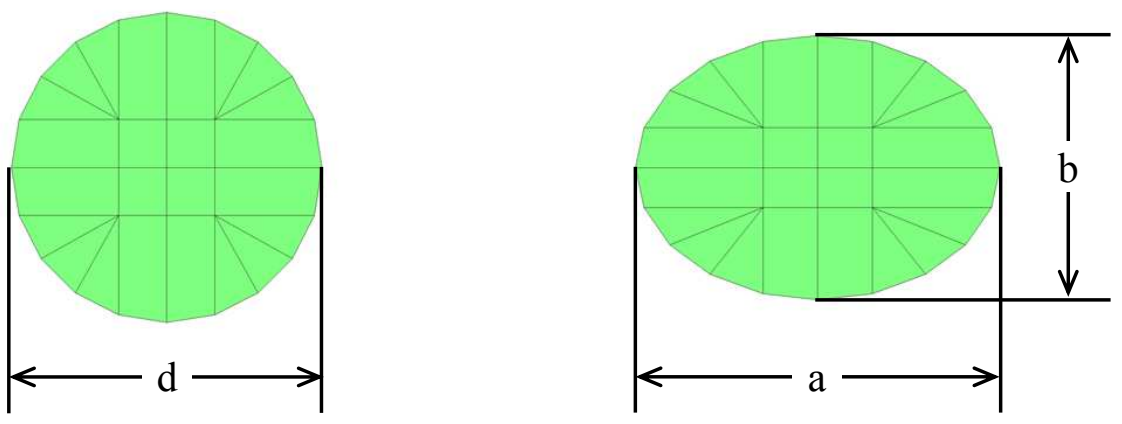

Figure 11: Shape and finite element divisions of isovolumetric elliptic cylindrical catalyst pellets with different $\beta$, the ratio of major axis to minor axis 
Figure 13 displays the average equivalent stress ratio of the elliptic cylindrical catalyst pellets with different $\beta$ to the circular cylindrical catalyst pellets. The horizontal axis is $\beta$, and the vertical axis is the average equivalent stress ratio of the elliptic cylindrical catalyst pellets to the circular cylindrical catalyst. It is seen that the average equivalent stress is the smallest when $\beta$ is about 1.45 . Compared to the circular cylindrical catalyst pellets, the elliptic cylindrical catalyst pellets with $\beta$ of about 1.45 have a further $2 \%$ decrease in the average equivalent stress.

From the above simulation results, it is clarified that the bulk density is the maximum value and the average equivalent stress is the minimum value when $\beta$ is equal to about 1.45 .

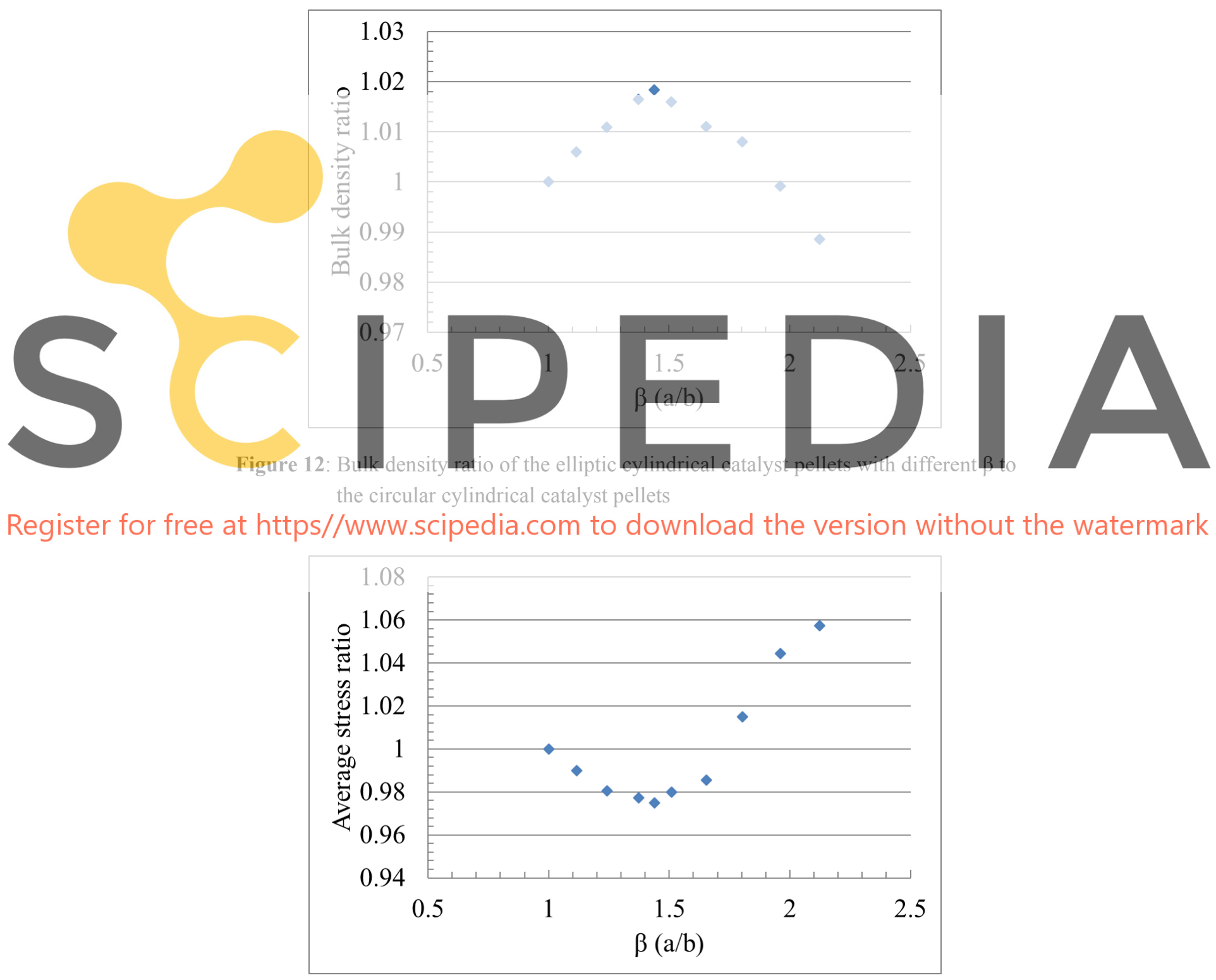

Figure 13: Average equivalent stress ratio of the elliptic cylindrical catalyst pellets with different $\beta$ to the circular cylindrical catalyst pellets 
That is, when the elliptic cylindrical catalyst pellets with $\beta$ of 1.45 are filled in the pipe reactor, the filled state of the catalyst pellets tends to be more uniform, and the durability of the catalyst pellets is expected to be higher due to the reduction of stress at the bottom of the pipe reactor.

\section{CONCLUSIONS}

In this paper, we evaluated the bulk density and the average equivalent stress distribution of the catalyst pellets filled in a pipe reactor with simulation methods based on the explicit FEM code LS-DYNA. We clarified the optimal shape for catalyst pellets based on simulation results. To summarize what we have covered, we can obtain the following findings.

- $\quad$ The average stress of catalyst pellets at the bottom of a pipe reactor approaches a constant value when the ratio of the filled catalyst pellets height to the pipe reactor diameter is greater than about 6.0.

Circular cylindrical catalyst pellets with a diameter-to-thickness ratio of 1.1 filled in a pipe reactor have the maximum bulk density and the minimum stress.

Elliptic cylindrical catalyst pellets with a major-minor axis ratio of 1.45 filled into a pipe reactor have the maximum bulk density and the minimum stress.

Compared to the circular cylindrical catalyst pellets, the elliptic cylindrical catalyst pellets with a major-minor axis ratio of about 1.45 have a further $2 \%$ increase in bulk density and $2 \%$ decrease in stress.
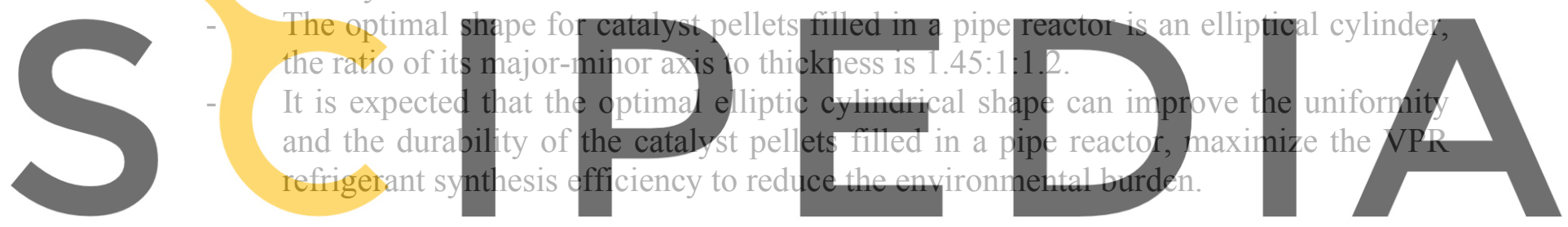

Register farfree latthttps//www.scipedia.com to download the version without the watermark

[1] https://hiranoyasan.com/all-items/industrial-catalyst/

[2] http://www.hanasaki.co.jp/products/entry-000168.html

[3] Jihong Liu, Optimization of resin pellet shape for improving flowability, WCCM2018Abstracts-FINAL, 13th World Congress on Computational Mechanics (WCCM XIII) and 2nd Pan American Congress (PANACM II), 1853-1863, July 22-27(2018), New York City, NY, USA.

[4] Jihong Liu, Optimization of Resin Pellet Shape for High Performance LAN Cable Manufacturing in the IoT Era, USNCCM15 Abstracts, $15^{\text {th }}$ U. S. National Congress on Computational Mechanics (2019), 452.

[5] Jihong Liu, Shape optimization of resin pellets for communication cable wire coating in IoT, $5 \mathrm{G}$ era (Improving flowability of resin pellet in a hopper). The proceedings of the 32nd Computational Mechanics Conference (CMD2019, JSME), No.19-19, F01-4 (2019).

[6] LSTC, LS-DYNA KEYWORD USER'S MANUAL VOLUME I \& II, Version R7 (2013). 